\title{
THE COMMUNICATIVE ACTS OF SYMPATHY AND CONDOLENCE IN ENGLISH AND BULGARIAN- PRAGMALINGUISTIC ASPECTS
}

\section{Deyana Peneva ${ }^{1}$}

\begin{abstract}
The present paper dwells on the speech acts of sympathy and condolence in English and Bulgarian and more precisely, on a set of certain phrases typical for both languages which reveal disparities in their grammatical, semantic and pragmatic structures. In particular, a distinction is made between two main phrases, namely, $\mathbf{M y}$ sympathies [+/- complement] and My condolences [+/- complement] in two sets of modern TV series (Bulgarian and British). It investigates the communicative acts into the group of expressive speech acts which can manifest a specific psychological state and attitude on the part of the speaker. The article also sheds light on the way native speakers of English use sympathy and condolence in utterances in comparison with their counterparts in Bulgarian with regards to their illocutionary nature. A further point of examination and speculation is the context of the speech situation, which in turn, may reveal cultural and psychological distinctions in a cross-linguistic study.
\end{abstract}

Key words: condolence, pragmatics, illocutionary force, speech act, sympathy

\section{Introduction}

In the sphere of speech act manifestations and events there are two basic features, the propositional attitude and illocutionary character, which are of crucial importance for the proper comprehension and digestion of the communicative force of the utterance. As the main function of each utterance is to serve as communication medium and convey certain goals related to communicative needs, in interaction patterns the participants in the speech situation make use of language variation in order to achieve certain purposes. In that respect, utterances which express sympathy or condolence may elicit a number of semantic meanings and pragmatic uses which could be socially and culturally bound to a definite language environment.

The present paper is an attempt to make a linguistic presentation to the concept of sympathies and condolences in English and Bulgarian with regard to both

1. Assistant Prof., Ph.D., Department of English Studies, Shumen University, Bulgaria, email: d.peneva@shu.bg, ORCID: 0000-0002-5321-0787 
phrases. It further dwells on the propositional and pragmatic aspects in the specific grammatical structures within the two languages.

\section{Previous Research In The Field}

Though the number of speech act research works is quite huge in the area of cross-cultural semantics and pragmatics, the linguistic resources in sympathy and condolence speech acts are limited as they illustrate social phenomena and psychological states which are culturally and ethnically oriented. On the other hand, both phrases exist in most languages which can make them comparable and are susceptible to parallel analysis. The paper sheds light on the way native speakers of English use sympathy and condolence utterances in comparison with their counterparts in Bulgarian. The importance of this study is crucial since there are few papers on the topic published by Bulgarian scholars (Slavyanova, 2017), which do not cover the academic aspect of the given paper.

In general, the speech acts of sympathy and condolence fall into the group of expressives (Searle, 1975, p. 59-78) (behabitives by Austin, 1962) which manifest a specific mental condition on behalf of the interlocutor/speaker, addresser/. Additionally, as behabitives they refer to the adoption of an attitude towards particular behavioral model that can be observed in society. Though both sets of communicative acts /of sympathy and condolence/ can be classified as expressive in view of their illocutionary force, this classification actually confines the utterances in question to a limited number of speech situations and investigates them separately instead of viewing them as an integral part of a bigger picture, that is, the context of the speech situation, which in turn, may reveal cultural and psychological distinctions in a cross-linguistic study.

Semantically, sympathies and condolences share similar meanings in that they refer to expressions illustrating a feeling of support for something or regret, or empathy to someone's pain, sorrow or grief (Muhammed, 2013). It could also be a case of showing compassion towards the addressee's misfortune or sadness (Zunin \& Zunin, 2007). On the other hand, though overlapping semantically to a great extent, the two sets of expressions reveal certain deviations in their uses as the first/sympathies/ can be viewed as a broader term while condolences mainly refer to acts of conscious support and active encouragement to the bereaved /the hearer/ concerning someone's death or adversity.

Both phrases also have a social function which is usually put down to their emotive character. Therefore, sympathy and condolence utterances use a specific type of language which is typical to phatic communication (Makice, 2009), less informative, more routinized and conventional, common in conversational exchanges, though possessing the essential condition (Yule, 2006, p. 45-49) of preserving politeness models in social discourse. 
In view of their communicative function, Austin attaches them to the class of expressives, later Searle to the group of behabitives, while Bach (2012) argues that they are related to "acknowledgments" in that, they may express attitudes which are considered convenient to the particular sort of occasion. Common to the three mentioned divisions is the expressive purpose of the acts and the sincerity condition (Turnbull, 2003, p. 56-57) that is illustrated. Additionally, it could hardly be a case of unsuccessful speech act, as the perlocutionary act that is expected on behalf of the addresser is supposed to be a speech act of acknowledgment as well (Bach \& Harnisch, 1979), being acknowledged, often "in satisfaction of a social expectation". For example:

"My most sincere sympathies to you and your family" - "I appreciate that."

Though both utterances are to be considered expressive acknowledgments if following the Bach and Harnisch's perspective the sincerity condition aspect could not be guaranteed fully as it mostly reflects the addresser's concerns than the addressee's. Interestingly enough, however, in the case of sympathies and condolences there could be two sincerity conditions, the first one associated with the feeling of sympathy for someone, while the second one is related to the social expectation that the addresser /the speaker/ is supposed to express that feeling for the hearer (Vanderveken, 1990).

As the present paper focuses on explicit performative utterances, that is, ones used in the first person singular, the expressions in question consist of two elements: a possessive adjective in the first person singular (my) and the respective noun in plural /the latter are derivative forms of the verbs sympathise and condole, accordingly/ and definitely bear a performative character.

\section{Research Questions}

A distinction is made between two main utterances, namely My sympathies [+/- complement] and My condolences [+/- complement] in two sets of examples taken from modern drama and action TV series /Bulgarian: Dyavolskoto garlo /The devil's throat/, Patyat na chesta /The way of honour/, Pod prikritie/Under cover - 34 episodes - 2014-2019/; British: The Capture, Fleabag, Killing Eve 34 episodes - 2013-2019/. For this paper the scenes that contain sympathy and condolence speech acts were excerpted and then analyzed focusing primarily on the respective expressions in question. A database of speech acts was compiled based on manual reading of the monologue and dialogue interactions and transcripts taken from both sets of data.

It should be taken into account that the processed data include only these two phrases and their syntactic combinations, i.e. the number of complements they could be coupled with. They are direct/explicit speech acts of either sympathy or condolence. All other grammatical structures which could precede the two 
utterances are not subject to discussion in the present paper, nor are any indirect communicative acts.

There are several questions which the paper tries to find answers to or at least makes an attempt to shed light on focusing on certain comparative and contrastive markers from semantic and pragmatic perspective:

- Are there any grammatical distinctions in complement patterning in the given phrases in English and Bulgarian;

- Are there any traces of semantic discrepancies in sympathy and condolence expressions identified in the comparative analysis;

- Are the respective expressions in Bulgarian show any shifts in pragmatic usage.

\section{Methods}

The elicited linguistic material was classified and examined on the basis of QQCA (quantitative and qualitative corpus analysis) (Biber \& Conrad, 2001, p. 331-336) (of sympathies and condolences in English and Bulgarian along with some ambiguities inherent in the respective languages. This analysis in turn may provide reflections on the behavior of both languages in their contextual, syntactic and pragmatic usages. In this regard, quantitative research findings can be generalized in a comparative mode, between two corpora, providing relatively reliable results based on statistical information confined to the parameters of the excerpted material. Though the abovementioned method has its limitations, it could serve as a springboard to a more detailed investigation as it is often a precursor to a multi-method research (Schmied, 1993, p. 85-96).

A number of symbolic devices and abbreviations are used in the paper:

$\mathbf{C L}$ - clause; VP - verb phrase; $\mathbf{N P}$ - noun phrase ; $\mathbf{P P}$ - prepositional phrase ; $\mathbf{P}$ - pattern

\section{Data Analysis}

- The expression "my sympathies" in English and Bulgarian

The expression My sympathies in the English language is composed of two lexical elements, the possessive adjective my in the first person singular coupled with a NP in plural - sympathies, which holds the semantic features [-animate], [+abstract], [+concrete], [+number] which in fact lacks the feature [+animate], consequently [+human]. However, the aspect of animate presence and attitude in the phrase can be felt, though implicitly, due to the influence of the adjacent possessive determiner which reveals a human interference due to contextual factors. For example:

ex. My sympathies to you, Maya, for the anguish you went through. /Fleabag - Br/ 
To this end, 73 examples were extracted from the British movies compared to 24 translation instances from the Bulgarian set of data. The respective wordfor-word translations equivalent to the English expression in Bulgarian is: Moite sachuvstviya or Moite saboleznovaniya. In the following two examples, though, only the first meaning is explicated:

ex. Moite sachuvstviya kum bednoto dete. /The way of Honour - Bg/

ex. Moite sachuvstviya za prezhivyanoto. /The way of Honour - Bg/

As a point of orientation, all of the respective sympathy expressions were collected, then grouped together and divided into grammatical patterns in view of their complementary endings. Three basic syntactic formats become explicit in English comprising a number of complement elements which further subdivide the basic patterns:

\section{P1 ms $_{\text {in }}$ mympathies + zero complement}

ex. My sympathies. I'm sorry, the meeting took much longer than expected. /Killing Eve-Br/

\section{P2 $2_{\text {ms }} \quad$ my sympathies + PP}

$\underline{\mathrm{P} 2 \mathrm{a}_{\mathrm{ms}}}:$ my sympathies + prep (for) $+\mathrm{NP}$ :

ex. My sympathies for your loss, Brian. /The Capture-Br/

$\underline{\mathrm{P} 2 \mathrm{~b}_{\underline{\mathrm{ms}}}}:$ my sympathies + prep $($ for $)+$ what $+\mathrm{CL}$ :

ex. My sympathies for what you have experienced. /Fleabag $-\mathrm{Br} /$

$\underline{\mathrm{P} 2 \mathrm{c}_{\mathrm{ms}}}:$ my sympathies + prep (to) $+\mathrm{NP}$ (person) $+[$ Prep (for) + what-CL]:

ex. My sympathies to you and your partner for what the company had to get over. /Fleabag - Br/

\section{P3 ms $^{\text {: }}$ my sympathies + VP}

P3a $_{\mathrm{ms}}:$ my sympathies + VP (be) + prep (with) + NP (person):

ex. My sympathies are with you and the bereaved. /The Capture - Br/

${\underline{\mathrm{P}} 3 \mathrm{~b}_{\mathrm{ms}}}_{\mathbf{s}}=$ my sympathies $+\mathrm{VP}$ (other) + prep (to) $+\mathrm{NP}$ (person)

ex. My sympathies go out to you and your son. /Killing Eve - Br/

The following table illustrates the distribution of cases in the pattern subdivisions and the respective percent values: 


\begin{tabular}{|l|l|l|}
\hline pattern & number of cases & percent value \\
\hline P1 MS + zero complement & 16 & 21.9 \\
\hline P2a MS + for + NP & 2 & 2.73 \\
\hline P2b MS + for + what +CL & 10 & 13.7 \\
\hline P2c MS+ to + NPp + [other] & $11+2$ & 17.8 \\
\hline P3a MS + be + with + NPp & 2 & 2.73 \\
\hline P3b MS + VP + to + NPp & 30 & 41.09 \\
\hline Total & 73 & $100 \%$ \\
\hline
\end{tabular}

It becomes clear that $\mathrm{P} 3 \mathrm{~b}_{\mathrm{ms}}$ pattern occupies the leading position with 30 out of 73 cases, followed by $P 1_{m s}$ with 16 utterances and $P 2 c_{m s}$ with 13 while $P 2 b_{m s}$ ranks fourth in the table with 10 cases. At the bottom of the scale are $\mathrm{P} 2 \mathrm{a}_{\mathrm{ms}}$ and $\mathrm{P3a}_{\mathrm{ms}}$ sharing equal numbers of utterances, only 2 .

In general, pattern $1\left(\mathrm{P}_{\mathrm{ms}}\right)$ stays isolated from the other two patterns as it does not take any complement forms whereas the two other groupings are actually grouped between a complement clause starting with a preposition and a verbal phrase succeeded by a complement structure. Interestingly enough, all six grammatical formats show deviations in the standard SVO syntactic sentence structure. Indeed, some of the sub-patterns do not possess a verb phrase $\left(\mathrm{P} 2 \mathrm{a}_{\mathrm{ms}}\right.$, $\mathrm{P} 2 \mathrm{C}_{\mathrm{ms}}$ ) succeeding the subject of the sentence.

With respect to $\mathrm{P} 1_{\mathrm{ms}}$ first, it is obvious that the syntactic structure of the sentence: $\mathrm{NP}+\varnothing \mathrm{VP}$ cannot actually refer to a complete full-clause format, though, it can still be considered a valid sentence, namely, a nominal sentence, which is verbless. Such sentences are typical in speech act communication. In 7 out of 16 cases the phrase refers to someone's death.

In terms of $\mathrm{P} 2_{\mathrm{ms}}$, in all three syntactic formats the complement element begins with a preposition, either for or to. While in $\mathrm{P} 2 \mathrm{a}_{\mathrm{ms}}$ and $\mathrm{P} 2 \mathrm{~b}_{\mathrm{ms}}$ the preposition is for, in $\mathrm{P} 2 \mathrm{c}_{\mathrm{ms}}$, it is to, which in turn shows that in $\mathrm{P}_{2} \mathrm{a}_{\mathrm{ms}}$ and $\mathrm{P} 2 \mathrm{~b}_{\mathrm{ms}}$ cases the speaker by expressing a certain feeling of sympathy would rather report first the tragic or unfortunate event rather than address first the person who is experiencing it, which is the case in $\mathrm{P}_{2} \mathrm{c}_{\mathrm{ms}}$. Another point of concern is that whereas in $\mathrm{P}_{2} \mathrm{a}_{\mathrm{ms}}$ both examples refer to someone's death, in $\mathrm{P} 2 \mathrm{~b}_{\mathrm{ms}}$ all extracts mainly depict the emotive aspect of compassion, pity/sorrow or pain about someone's tribulations or adversity in life, but not someone's bereavement. As for pattern $\mathrm{P} 2 \mathrm{c}_{\mathrm{ms}}$, it becomes explicit with 11 cases in MS + to +NP (person) sentence structure and 2 utterances following the same sentence format succeeded by a prep (for) + what-clause in which the person affected and the negative event are mentioned. In all, 6 out of $13 \mathrm{P}^{2} \mathrm{c}_{\mathrm{ms}}$ utterances are associated with the feeling of sympathy to a bereaved while the other examples are mostly related to one's misfortune and bad lack and can be linked to the feelings of sorry or pity. 
Taking $\mathrm{P} 3_{\mathrm{ms}}$ next, it reveals two complement extensions and is present in the corpus database with 2 cases in the grammatical structure: $\mathrm{P} 3 \mathrm{a}$ : MS + the link verb be added to a prepositional phrase (PP), namely, the preposition with in combination with an object pronoun you. The latter bears the grammatical characteristics of a declarative sentence format alongside a declarative plus expressive speech act illocutionary force in that the speaker wants the propositional content of the act to induce a certain /psychological/ effect on the hearer. Actually, by expressing sympathies, in $\mathrm{P}_{\mathrm{ms}}$ pattern, the speaker aims to show compassion and empathy to the hearer's grief /both examples refer to someone's death/, although they sound a bit ritualized and formal. However, they are not common among British speakers and can be considered single isolated cases of sympathy expressions. A similar syntactic structure is observed in $\mathrm{P} 3 \mathrm{~b}_{\mathrm{ms}}$ which occupies the leading position and gains prominence over the other syntactic structures. It, in fact, comprises the same grammatical constituents arranged in the same order as in $\mathrm{P} 2 \mathrm{a}_{\mathrm{ms}}$ : MS + VP + PP, however the verb phrase becomes explicit in the phrasal verb go out /in all cases/ linked to the preposition with and you as the object pronoun. $\mathrm{P} 3 \mathrm{~b}_{\mathrm{ms}}$ pattern further shares the same structural specificities of a declarative sentence and propositional attitude. Pragmatically, though, it is widely used and exploited in cases of showing sympathies to the bereaved.

In general, there are 47 examples in the English corpus which mean commiserating with someone who has experienced the death of a very close person whereas there are 26 cases illustrating compassion or sympathy to other misfortune acts.

With regard to the Bulgarian equivalent of the English My sympathies Moite sachustviya/ saboleznovaniya, the latter (saboleznovaniya) depicts two grammatical formats in Bulgarian which copy P1 (15 cases out of 24) and P2a (1 case) and P2b (8 out of 24) complement structures in English. There are no cases illustrating P3 structures. Obviously, the expression in that form is not so popular among Bulgarian speakers. The table below shows the distribution of cases and the respective percent values of the identified patterns:

\begin{tabular}{|l|l|l|}
\hline pattern & number of cases & percent value \\
\hline P1 MS + zero complement & 15 & 62.5 \\
\hline P2a MS + za+ NP & 1 & 4.2 \\
\hline $\begin{array}{l}\text { P2b MS + za + tova, koeto } \\
\text { +CL }\end{array}$ & 8 & 33.3 \\
\hline Total & 24 & $100 \%$ \\
\hline
\end{tabular}

Pattern 1 becomes explicit with 15 examples, 7 of which are related to the act of showing sympathy to someone who has experienced the death of a loved one. The phrase is routinized and clichéd and as there is no complement tailing, the expressive mood and the particular personal attitude towards the hearer are 
not that noticeable. It sounds more distant and socially detached, although the contextual surrounding may change that emotive power.

The following sentences are examples of $\mathrm{P} 2 \mathrm{a}$ and $\mathrm{P} 2 \mathrm{~b}$ patterns:

ex. Moite sachuvstviya za tezhkata zaguba. /My sympathies for your terrible loss.//Under cover - Bg/, where the Bulgarian sentence is a word-for-word translation equivalent of the English one, in that all syntactic constituents are identical (P2a).

ex. Moite sachuvstviya za tova, koeto si prezhivyal. /My sympathies for what you have lived through.//The devil's throat - Bg/ (P3a)

In the latter case there are certain aberrations in the grammatical transfer as well as in the lexical equivalence, namely, in the prepositional complement clause after the performative utterance: the phrase za tova, koeto is translated in English for what, though the literal translation should be for that, what. While in Bulgarian there are two elements, tova and koeto, which apply to one and the same entity in the world and propositional content, giving explanation for the act of sympathy and its reference with regard to the hearer's grief/pain, the English translation comprises only one such lexical element which also serves as an explanatory account for the act of showing sympathy. Nevertheless, that disparity cannot be considered a marked one but could contribute to the overall picture of grammatically correct strategies where the purely routinized formulas /as in English/ would sound more distant to the hearer. Additionally, though the declarative nature of the sentence is obvious, the expressive aspect prevails. While there are 7 cases of $\mathrm{P} 1$ pattern which refer to a bereaved person, all other 17 utterances refer to someone's misfortune or tragic ordeal, but not to someone's death. Interestingly enough, however, the Bulgarian expressions of that syntax and lexical content are not typical as a whole. They are more common in other grammatical structures preceding the performative parts.

\section{- The expression "my condolences" in English and Bulgarian}

The discussion and analysis of the second phrase in question is limited pragmatically as it can only be used in cases when the addresser's communicative goals refer to someone suffering from the loss of a dear person. All other contextual options, either of illustrating compassion or sympathy cannot be traced in the expression. That is valid for both languages.

In terms of semantic content, the translation equivalent of the expression $M y$ condolences is Moite saboleznovaniya in Bulgarian, the latter bearing the same propositional content as in its English counterpart phrase. The nouns condolence and saboleznovanie contain the prefixes (con-) (Baerman, 2015, p. 34) and (sa-) (Nitsolova, 2008) (with the meaning "joined to something") which appended to the root morpheme (-dol-En; -bol-Bg) with the meaning "pain", become identifiable as linguistic entities possessing certain propositional attitude as 
emotional expressions Consequently, the two nouns apart from expressing sympathy or compassion, also imply the idea of empathy that involves the speaker emotionally into the pain of the sufferer /addressee/ (Jadhav, 2013). Taken in isolation, both expressions sound trivial, commonplace, customary, though contextually, they may display a stronger emotional contour and emotive power as the contextual factors such as social distance and relationship to the bereaved or the deceased may be quite determinative.

Syntactically, the English expression falls into two main complement structures:

\section{$P 1_{\mathrm{mc}}$ : My condolences + zero complement \\ $\mathbf{P} 2_{\mathrm{mc}}$ : My condolences $+\mathbf{P P}\left[\right.$ to/on/for $\left.+\mathrm{NP}_{\text {person/ther }}\right]$ \\ ex. My condolences on the death of your father. /The Capture - Br/}

The overall number of examples is 42 with $\mathrm{P} 1_{\mathrm{mc}}$ indicating 5 cases whereas the other 37 utterances are distributed among the $\mathrm{P} 2_{\mathrm{mc}}$ subpatterns.

In the event of $\mathrm{P} 1_{\mathrm{mc}}$ pattern, the performative entity does not take any complement markers which on its part does not show any further expressive emphasis implied by the communicative act. That is considered to be a pure form of declarative self-evident form of a standard expression. The emotional aspect can only become explicit if the utterance is followed by additional communicative acts as it is the case in the following example:

ex. My condolences. Accept my heartfelt sympathies. You know, my heart goes out to you. I promise I will not let you be alone with your pain. /Killing Eve - Br/

Indeed, the performative phrase is succeeded by three other utterances: a direct act of sympathy; an implicit act of sympathy/condolence and a promise /which is a commissive speech act/, adding a more personal attitude and illustrating limited social distance to the hearer.

Regarding $\mathrm{P} 2_{\mathrm{mc}}$ next, my condolences plus a prepositional phrase, the pattern falls into three possible sub-structures. It keeps its syntactic format but replaces one lexical item with another one which belongs to the same part of speech. In that case, the item that is to be replaced is the preposition of the prepositional phrase which as a function word cannot change the grammatical structure of the utterance but may cause propositional deviations. In that respect, the three P2 sub-branches are as follows:

$$
\begin{aligned}
& \text { P2a } \mathbf{m c}_{\text {mc }} \quad \mathrm{MC}+\text { to-NP }{ }_{\text {person }}+\left[\text { for }+\mathrm{NP}_{\text {other }}\right] \text { : } \\
& \text { ex. My condolences to you and your son. /The Capture }-\mathrm{Br} / \\
& \text { P2b } \mathbf{b}_{\text {mc }} \text { : } \quad \mathrm{MC}+\text { on-NP } \mathrm{N}_{\text {other }} \\
& \text { ex. My condolences on your friend's passing. I vividly remember every }
\end{aligned}
$$


P2c $_{\mathrm{mc}}$ : $\mathrm{MC}+$ for-NP $\mathrm{N}_{\text {other }}$

ex. My condolences for his terrible sorrow. The Capture $-\mathrm{Br}$ /

The number of cases and their respective percent rates are presented in the table below:

\begin{tabular}{|l|l|l|}
\hline pattern & number of cases & percent value \\
\hline P1a ${ }_{\mathbf{m c}} \mathrm{MC}+$ zero complement & 5 & 11.9 \\
\hline P2a $_{\mathbf{m c}} \mathrm{MC}+$ to-NP & 6 & 14.3 \\
\hline P2bron $_{\mathbf{m c}} \mathrm{MC}+$ on-NP $_{\text {other }}$ & 28 & 66.7 \\
\hline P2c $_{\mathbf{m c}} \mathrm{MC}+$ for-NP & 7.1 \\
\hline Total & 3 & $100 \%$ \\
\hline
\end{tabular}

The most common expression, obviously, is the $\mathrm{P} 2 \mathrm{~b}_{\mathrm{mc}}$ with 28 out of 47 cases. With respect to its semantic attitude, it actually copies the pattern My sympathies + for $+N P_{\text {other }}$ as the propositional content addresses not directly the addressee, but his/her suffering. The interesting thing here is that while my sympathies expression is common with the preposition for, my condolences mostly goes with on, which in itself could hardly reveal any pragmalinguistic disrepancies. Relevantly, the $\mathrm{P} 2 \mathrm{c}_{\mathrm{mc}}$ pattern reveals a similar semantic aspect to $\mathrm{P} 2 \mathrm{~b}_{\mathrm{mc}}$ with the preposition for succeeded by a nominal phrase lacking the semantic feature $[+$ animate] by referring to an event.

During the process of analysis, it became evident that the difference between using on or for refers to certain contextual determinants, in that, in a face-toface communication when the speaker refers directly to the misfortunate event talking to the hearer, the more preferable preposition is on, while for is more favoured as a second-hand reported phrase. For instance:

ex. My condolences on your recent loss. /The Capture $-\mathrm{Br}$ /

ex. My condolences for her family in this awful situation. /The Fleabag/

Personally, since the for expressions extracted from the movies were uttered by non-native speakers of English /an Italian and two Indian employees/, it could be assumed that there is either an incorrectly used lexical item, or an adopted piece of lexical knowledge typical to American English. It should also be mentioned that the performative phrase also collocates with the prepositions over and upon which are mainly recognizable if the expression is preceded by a verb phrase / offer, accept/.

In terms of the Bulgarian equivalent of "my condolences", that is, Moite saboleznovaniya, the expression becomes explicit with the same complement structures: 1. MS + zero complement; 2. MS + na-NPperson; 3. MS + za- 
NPother. The number of cases and their distribution percent values are given in the following table:

\begin{tabular}{|l|l|l|}
\hline pattern & number of cases & percent value \\
\hline 1. MS + zero complement & 14 & 77.2 \\
\hline 2. MS + na+ NPperson & 2 & 11.1 \\
\hline 3. MS + za + NPother & 2 & 11.1 \\
\hline Total & 18 & $100 \%$ \\
\hline
\end{tabular}

The zero-complement pattern gains prominence over the other mono-valent prepositional noun phrases in the Bulgarian language. Essentially, both the prepositions na (followed by a [+animate, +human] NP) and za (succeeded by a NPevent) are not conventional in a face-to-face interaction. As contextually the expression is used mainly when showing sympathies to someone's death. The phrase is routinized and stable with relevance to the socially accepted set of expressions in such pragmatic environment. The emotive contour and the expressive aspect are less distinct. Another aspect is that one of the issues which could make a condolence utterance more complicated is the relationships between the interlocutors. In order to report a meaningful sentiment showing a personal regard to the bereaved, further utterances should be added. That is not the case in the Bulgarian set of data. Similarly, English data illustrate also less expressive personal attitude. Characteristically, other forms or expressions of sympathy are needed to enhance the emotional content of an expression.

\section{Results/ Key Findings}

After investigating the two sets of data in a comparative mode the following results were found out:

With respect to the expression My sympathies:

- in general, English speakers outperformed Bulgarian speakers into a ratio roughly three to one $/ 73$ compared to 24 cases/, which makes the phrase more common in British language surrounding limited to the corpus data;

- nearly two thirds of English utterances express sympathies to a bereaved (47 compared to 26 examples) while the incidence in Bulgarian illustrates an opposite trend (7 utterances referring to someone's loss in contrast to 17 other reason cases);

- semantically, no significant differences were found between the two phrases /English and Bulgarian/;

- the prevalent pattern in English obtained in this research is My sympathies + verb phrase + prepositional phrase [to+person], whilst in Bulgarian it is Moite sachuvstviya + zero complement.

- pragmatically, the expression is widely used among native speakers 
of English to express condolences and compassion, while Bulgarian natives rarely use it to express condolences.

- in both languages the expression has a high degree of expressive power.

With respect to My condolences the results from the analysis are the following:

- obviously, the English database outnumbers the Bulgarian set of condolence utterances significantly /42 compared to 18 examples/ in the analyzed corpus;

- English speakers when expressing condolences seem to emphasize on the event while Bulgarians tend to exploit the expression neutrally without any complements addressing the event or the bereaved;

\section{Conclusion and Implications}

The elicitations of this article, though limited in scope, may contribute to:

- both teachers and learners to distinguish the semantic and syntactic nuances of sympathies and condolences separately and relate them to a specific emotional state /anger, pain, pity, sorrow, sympathy/;

- learners' linguistic awareness of the foreign language with respect to given syntactic structures of specific speech acts, which in turn could be essential for students in mastering pragmatic competence.

\section{References:}

Austin, J. L. (1962). How to do things with words. London: Oxford University Press.

Bach, K. (2012). Speech Acts. Retrieved from http://www.online.sfsu.edu/ $\mathrm{kbach} / \mathrm{spchacts.html.}$

Bach, K., \& Harnish, R. M. (1979). Linguistic communication and speech acts. Cambridge, Mass.: MIT Press. Pragmatic Transfer. Second language Research, 8, 203-231.

Baerman, B. (2015). The Morpheme. Surrey: Oxford University Press.

Biber, D., \& Conrad, S. (2001). Quantitative corpus-based research: Much more than bean counting. TESOL Quarterly, 35(2), 331-336.

Muhammed, S. E. (2013). Condolences in English. Journal of Kerbala University, 11 (4), Humanities.

Jadhav, A. (2013). Condolence Phrases. Retrieved from http://buzzle.com/ articles/condolence-phrases.html. 
Makice, K. (2009). Phatics and the design of community. Proceedings of the 27th international conference extended abstracts on Human factors in computing systems. Boston, MA, USA.

Nitsolova, R. (2008). Balgarska gramatika. Morfologiya. Sofia: Kliment Ohridsky University Press.

Schmied, J. (1993). Qualitative and quantitative research approaches to English relative constructions. In C. Souter \& E. Atwell (Eds.), Corpus-based computational linguistics, (pp. 85-96). Amsterdam: Rodopi.

Searle, J. R. (1975). Indirect speech acts. Syntax and semantics Vol. 3. Speech acts. (pp. 59-78). New York, San Francisco, London: Academic Press.

Slavyanova, L. (2017, April 7). Analiz na rechevite etiketni edinitsi za podnasyane na saboleznovaniya $\mathrm{v}$ angliyskiya i balgarskiya ezik. LiterNet, 4(209). Retrieved from https://liternet.bg/publish31/liliana-slavianova/analiz. htm.

Turnbull, W. (2003). Language in action: Psychological models of conversation. International Series in Social Psychology. Routledge, 56-57.

Vanderveken, D. (1990). Meaning and Speech Acts. Vol. I. Cambridge: Cambridge University Press.

Yule, G. (2006). The study of language (3rd ed.). Cambridge: Cambridge University Press. 45-49.

Zunin, L. M., \& Zunin, H. S. (2007). The art of condolence. What to write, what to say, what to do at a time of a loss. London: Harper Collins Publishers Ltd. 